\title{
Influence of Light Wavelengths on Visibility in Smoke during a Tunnel Fire
}

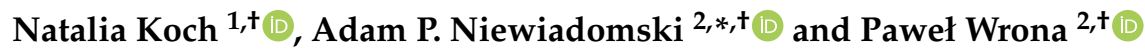 \\ 1 Independent Researcher, 42-580 Wojkowice, Poland; natalia_koch@poczta.onet.pl \\ 2 Faculty of Mining, Safety Engineering and Industrial Automation, Silesian University of Technology, \\ 44-100 Gliwice, Poland; pawel.wrona@polsl.pl \\ * Correspondence: adam.niewiadomski@polsl.pl \\ + These authors contributed equally to this work.
}

Citation: Koch, N.; Niewiadomski, A.P.; Wrona, P. Influence of Light Wavelengths on Visibility in Smoke during a Tunnel Fire. Sustainability 2021, 13, 11599. https://doi.org/ $10.3390 /$ su132111599

Academic Editors: Aleksander Król and Małgorzata Król

Received: 27 September 2021

Accepted: 18 October 2021

Published: 20 October 2021

Publisher's Note: MDPI stays neutral with regard to jurisdictional claims in published maps and institutional affiliations.

Copyright: () 2020 by the authors. Licensee MDPI, Basel, Switzerland. This article is an open access article distributed under the terms and conditions of the Creative Commons Attribution (CC BY) license (https:/ / creativecommons.org/licenses/by/ $4.0 /)$.

\begin{abstract}
The occurrence of fire in road tunnels poses high risks to the life and health of people. The resulting smoke, fire gases and high temperatures can be the cause of poisoning and burns. Additionally, dense smoke can significantly reduce visibility, which can result in difficulties during evacuation. This paper aims to investigate the effect of specific wavelengths of visible light on visibility in smoke conditions and to determine the wavelength of light (colour) that can improve visibility in smoke-filled environments. A rubber mixture with polyester and polyamide spacers was selected as a combustible material in order to obtain more realistic conditions with respect to smoke parameters. These plastics are commonly used, among others, in tires, elements of engine plating, upholstery or truck trailer covers. Then, in a test fire chamber laboratory, the colour of light (wavelength) was determined, obtaining the highest transmittance value, understood as the amount of radiation transmitted through the substance. It has been shown that devices emitting a light wave of a specific length can significantly improve visibility in smoke-filled environment.
\end{abstract}

Keywords: fire; fire in road tunnel; visibility in smoke; light wavelength; fire safety

\section{Introduction}

The fire safety problem in traffic tunnels is the subject of extensive research and analysis presented in many scientific publications. In recent years, the key research directions include the analyses of tunnel ventilation performance in the event of a fire and the analyses of fire smoke spread [1-4]. Other major directions include technical solutions for reducing smoke density in the tunnel interiors and improving the effectiveness of rescue operations [5-8], organizational solutions and procedures aimed at reducing risk level [9,10] or analyses the effectiveness of both self-evacuation and rescue operations [1,11-13]. A fire in traffic tunnels is always associated with an increase in the risk of people and emergency services operating in the area being trapped inside. The smoke produced during a fire can significantly reduce visibility and, consequently, impede substantially effective evacuation. The number of fatalities in tunnel fire accidents shows how significant this issue is (Table 1).

Several documented fires in underground mines also followed a development pattern similar to the mentioned traffic tunnel accidents. In one such incident, two mine rescuers died in the Polish underground coal mine "Krupinski" in 2011. Their deaths were a result of losing orientation in dense smoke caused by underground fire [14].

In this study, the authors of this paper decided to focus on visibility improvement, which may result in higher evacuation efficiency and rescue team work effectiveness. Moreover, it can reduce the risk of disorientation in the danger zone. The research aimed to determine the effect of selected wavelengths of visible light in terms of visibility in smoke conditions and to determine the wavelength of light (colour) that improves visibility in a smoke-filled environment. The use of adequate light to enhance visibility in smoke can improve evacuation or rescue operations safety. 
Table 1. Example tunnel fire accidents causing fatalities (based on [15-17]).

\begin{tabular}{ccc}
\hline Date & Tunnel & Fatalities \\
\hline $1987 / 11 / 18$ & Kings Cross, London Underground, England & 31 \\
$1994 / 03 / 01$ & Huguenot Tunnel, South Africa & 1 \\
$1995 / 10 / 28$ & Baku, Azerbaijan & 289 \\
$1999 / 03 / 24$ & Mt Blanc, France/Italy & 39 \\
$1999 / 05 / 29$ & Tauern, Austria & 12 \\
$2000 / 11 / 11$ & Kaprun, Austria & 158 \\
$2001 / 08 / 06$ & Gleinalm Tunnel, China & 5 \\
$2001 / 10 / 24$ & St Gotthard, Switzerland & 11 \\
$2003 / 02 / 18$ & Daegu, South Korea & $197+$ \\
$2010 / 07 / 04$ & Huishan Tunnel, China & 24 \\
$2012 / 05 / 08$ & Xueshan Tunnel, China & 2 \\
$2014 / 03 / 01$ & Yanhou Tunnel, China & 40 \\
$2017 / 05 / 09$ & Taojiakuang Tunnel, China & 12 \\
$2019 / 08 / 25$ & Maoliling Tunnel, China & 5 \\
\hline
\end{tabular}

Research on visibility in smoke was conducted, inter alia, by Tadahisa Jun [18]. The author focused on the aspects of evacuation speed in a smoke-filled environment. On the other hand, Jin and Yamada [19] studied the effect of irritating fumes on visibility. The same authors [20] conducted experimental research on people's behaviour in evacuation from a smoke-filled corridor. In 2010, Qihui Zhang [21] investigated the effect of different light wavelengths on the visibility of a standardized barcode in smoke conditions. He focused more on the study of contrast fading for an evacuation sign seen in a layer of smoke and confirmed the results of Jin T. from 2008 [22]. This phenomenon was also the object of simulation studies, e.g., [23]. Previously mentioned studies have addressed the issue of seeing an object of a particular colour in smoke, while this paper addresses the issue of selecting the colour of light (wavelength) for improving visibility in smoke conditions.

\section{Experimental Procedure}

The study aimed to determine the wavelength of light (colour) that improves visibility in a smoke-filled area. The research involved the application of proprietary designed five light-emitting devices (Figure 1). They contained the following components:

- $\quad$ Power LEDs;

- Lenses;

- Heat sink;

- Housing.

The authors performed experiments in real smoke produced by combusting prepared identical samples containing rubber mixture with polyester and polyamide spacers. The choice of these materials commonly used in the automotive industry, among others, was dictated by the need to create conditions that could arise in the case of a traffic tunnel fire. All tests were performed in the dark (illuminance meter readings before testing were below $1.0 \operatorname{lux})$.
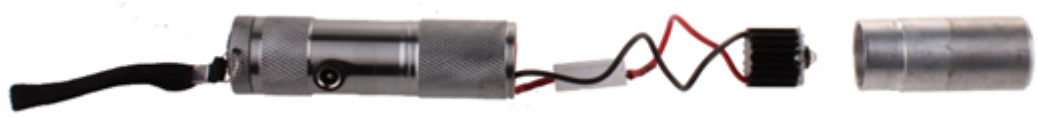

Figure 1. Light-emitting device construction.

The main components of the devices were power LEDs (high power LEDs) emitting light of a specific wavelength from the manufacturers ProLight Opto and Huey Jann Electronic in a star type housing. A summary of the used electronic components parameters is shown in Table 2. 
Table 2. Details of the installed Power LEDs.

\begin{tabular}{cccc}
\hline & Color & Wavelength $(\mathbf{m i n} / \mathbf{t y p} / \mathbf{m a x}) \lambda(\mathbf{n m})$ & Manufacturer \\
\hline 1 & ultraviolet & $390 / 400 / 410$ & ProLight Opto \\
2 & blue & $455 / 465 / 475$ & ProLight Opto \\
3 & green & $-/ 525 /-$ & Huey Jann Electronic \\
4 & amber & $587 / 592 / 597$ & ProLight Opto \\
5 & red & $613.5 / 623 / 631$ & ProLight Opto \\
\hline
\end{tabular}

An illuminance meter (lux meter) was also used for the measurements [24].

The model used in the research procedure was TES 1335 (Figure 2). The sensor used in it is a long-life silicon filter diode, which ensures stable measurement. The measurements made by the device are in units of lux (lux) and foot-candle (fc). The lux meter used as an instrument for measuring illuminance is very accurate, as reflected by comparing the spectral sensitivity characteristics of the device and the human eye (Figure 3). The spectral sensitivity characteristic of the optical sensor used (photodiode with filter) coincides closely with the $\mathrm{V}(\lambda)$ curve. The $\mathrm{V}(\lambda)$ parameter defines the eye's sensitivity, determined by the International Commission on Illumination, i.e., it is sensitive to waves in the visible light range, similarly to the human eye.

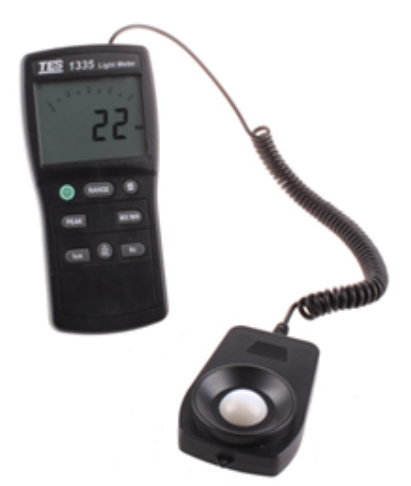

Figure 2. Lux meter TES 1335.

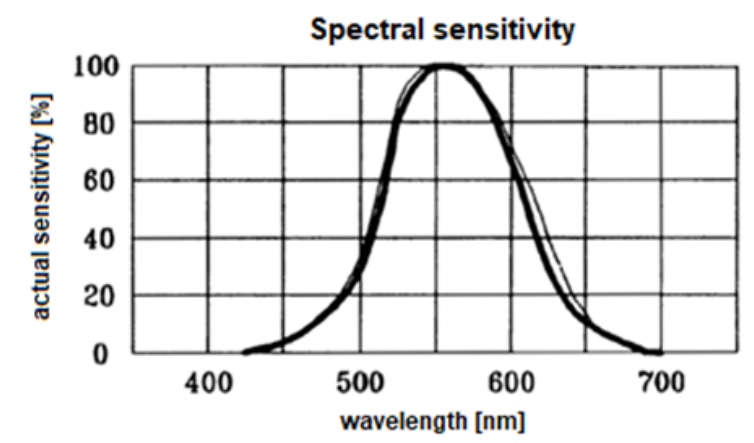

$\longrightarrow \mathrm{V}(\lambda)$
$\longrightarrow$ lux meter TES 1335

Figure 3. Spectral sensitivity characteristics of the lux meter [24].

\subsection{Test Fire Chamber Laboratory}

Experimental studies were conducted in the Test Fire Chamber of the Laboratory of Technical Fire Protection Systems in the State Fire Service Central School in Częstochowa (Figure 4). The Test Chamber's walls are constructed from glass panes in metal frames, bricks, concrete supports and ceiling. The dimensions of the chamber are $7.0 \mathrm{~m} \times 7.0 \mathrm{~m}$ $\times 3.0 \mathrm{~m}$, which produces approximately $150 \mathrm{~m}^{3}$ of volume. Moreover, a part of chamber 
equipment consists of black blinds that limit the access of light to its interior. The chamber houses three photoelectric device sensors (densitometer), $\mathrm{K}_{1}, \mathrm{~K}_{2}$ and $\mathrm{K}_{3}$, that are used to measure optical density. The densitometer is a custom construction ordered by the Central School of the State Fire Service. Its manufacturer also provided the necessary software. The applied radiation power band of the measuring light flux (infrared) is $\lambda=950 \mathrm{~nm}$. The diagram of the combustion chamber with the location of the $K_{1}, K_{2}$ and $K_{3}$ sensors is shown in Figure 5.

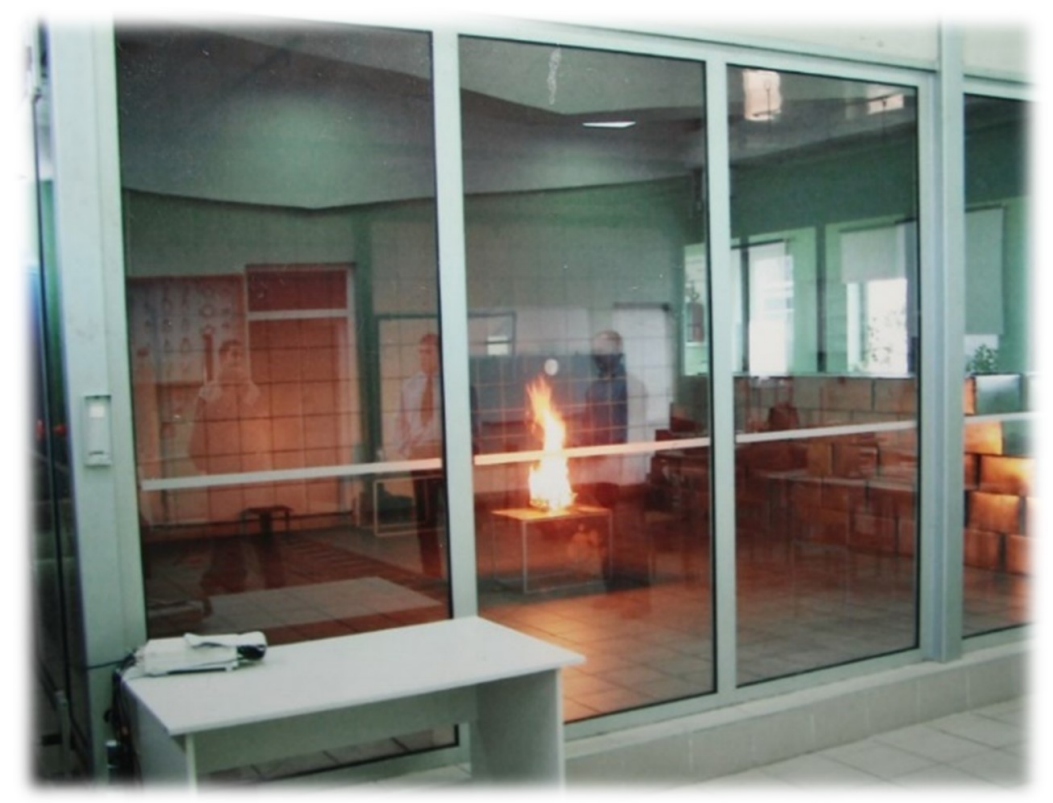

Figure 4. Test Fire Chamber in the State Fire Service Central School in Częstochowa.

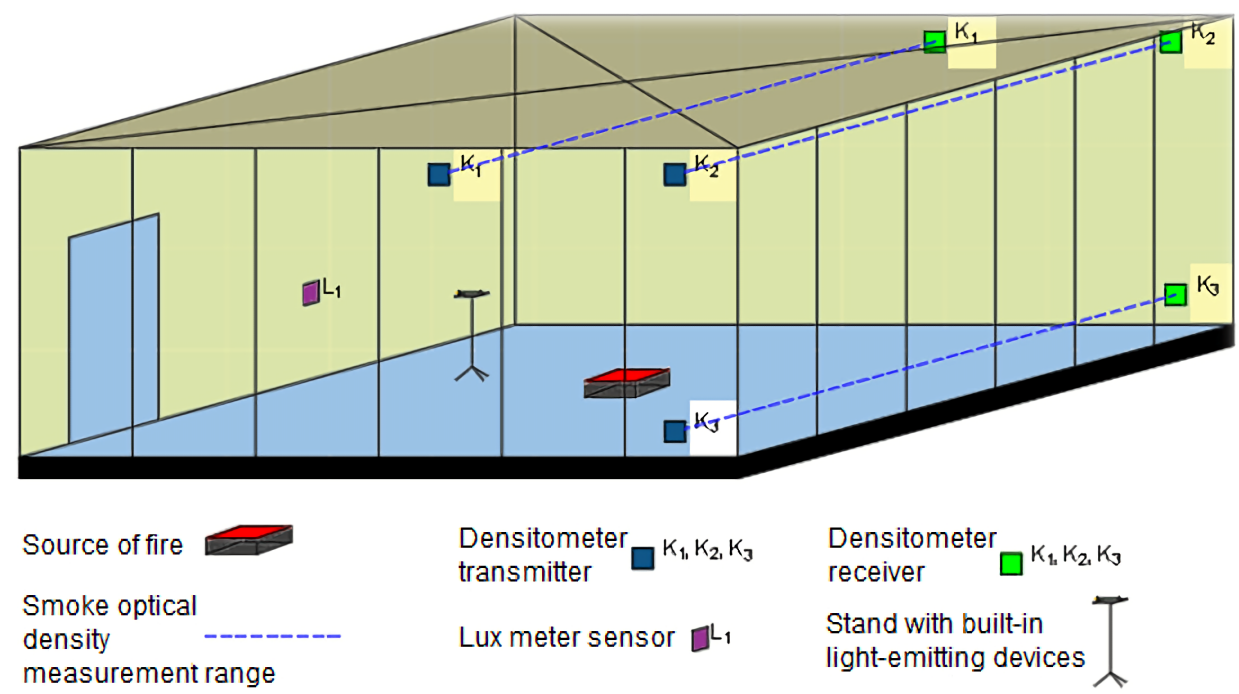

Figure 5. Overview of the test fire chamber.

The measuring site inside the Test Fire Chamber consisted of a stand with built-in light-emitting devices and light intensity meter (Figure 6). Some of the activities associated with operating the equipment and reading the measurements took place beyond the chamber for safety reasons (the wires have been routed outside through specially prepared sealed culverts). 


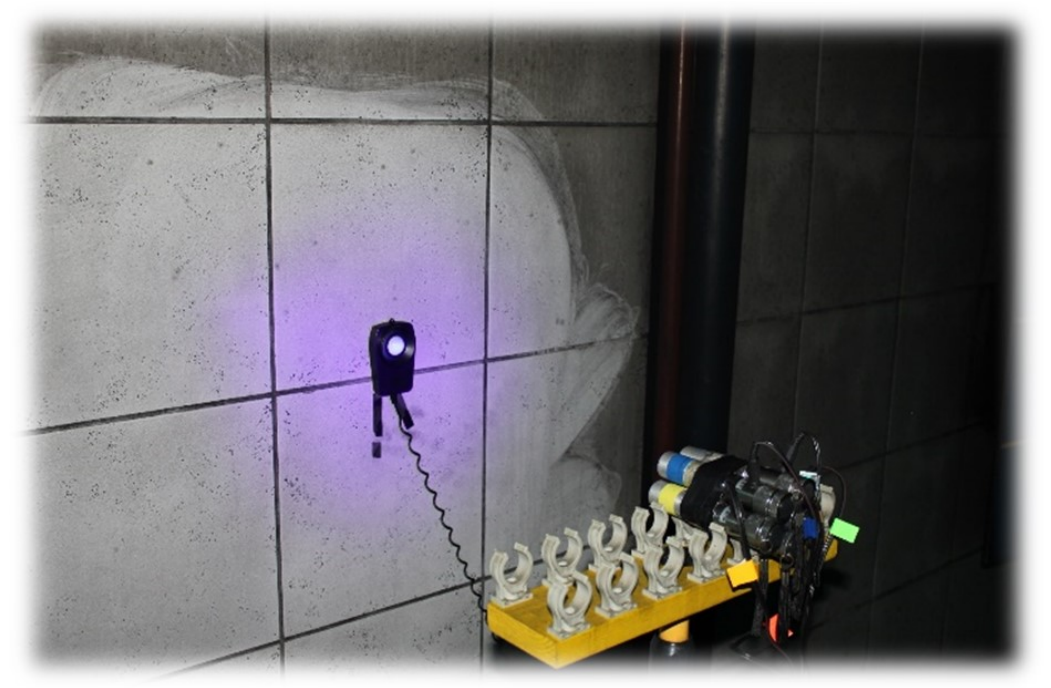

Figure 6. Measuring site inside the test fire chamber.

\subsection{Research Methodology}

The research methodology was based on determining the transmittance $\mathrm{T}$, which shows what part of the emitted radiation transmits through the substance. In this case, the measured values of illuminance E expressed in lux were used instead of luminous intensity I. Moreover, due to the sensitivity of statistical tests, transmittance values were presented as percentages $[25,26]$.

The illuminance measurements of devices emitting individual wavelengths were performed at five assumed distances: $0.4 \mathrm{~m}, 0.6 \mathrm{~m}, 0.8 \mathrm{~m}, 1.0 \mathrm{~m}$ and $1.2 \mathrm{~m}$. The measurements obtained at each given distance in the smokeless conditions were the reference points for developing the results. In contrast, the starting point of the smoke intensity measurements was set when readings on all three sensors of the densitometer indicated less than $0.5 \%$. The fire source in the Test Fire Chamber was located in its centre, i.e., $3.5 \mathrm{~m}$ from each wall. The photometric sensor of the $L_{1}$ lux meter was located at half the height of $1.0 \mathrm{~m}$ on the chambers' brick wall (i.e., $3.5 \mathrm{~m}$ in front of the fire source). The stand with light sources (devices with LEDs) was placed between them (perpendicular to the sensor of the lux meter). Its exact location varied depending on the distance from the photometric sensor at which the measurements were taken: $0.4 \mathrm{~m}$ ( $3.1 \mathrm{~m}$ away from the fire source), $0.6 \mathrm{~m}(2.9 \mathrm{~m}$ away from the fire source), $0.8 \mathrm{~m}$ ( $2.7 \mathrm{~m}$ away from the fire source), $1.0 \mathrm{~m}(2.5 \mathrm{~m}$ away from the fire source) and $1.2 \mathrm{~m}$ ( $2.3 \mathrm{~m}$ away from the fire source). The locations of the culverts and access to electricity were the main reason for placing the stand with light-emitting devices at the selected position.

According to the adopted procedure, before the start of combustion, the illuminance of all light-emitting devices was measured at the assumed distances. These measurements were performed in a chamber darkened by blinds and that was smokeless and previously ventilated. Then, the test fire was initiated, and the readings of the densitometer sensors were verified. The chamber's smoke status was also visually verified through the glass walls of the chamber. Per one test fire, one series of measurements was carried out, i.e., illuminance measurements were performed for individual wavelengths of light at all distances.

Two experts from the Central School of the State Fire Service participated in each measurement series. Firefighters were selected randomly, informed about the research purpose and adopted test procedure and their roles. During the test fire, they stayed inside the chamber, equipped with protective gear and operated the light-emitting devices. Between the operators and the coordinator outside, the chamber maintained constant radio contact. In addition to recording sensor measurements, this approach allowed additional subjective expert assessment of visibility change due to the various wavelengths of emitted light. 


\section{Results Analysis and Discussion}

The $\mathrm{T}_{E}$ transmittance values determined based on the measurements made at selected distances and in individual series were averaged and then presented in Figure 7.

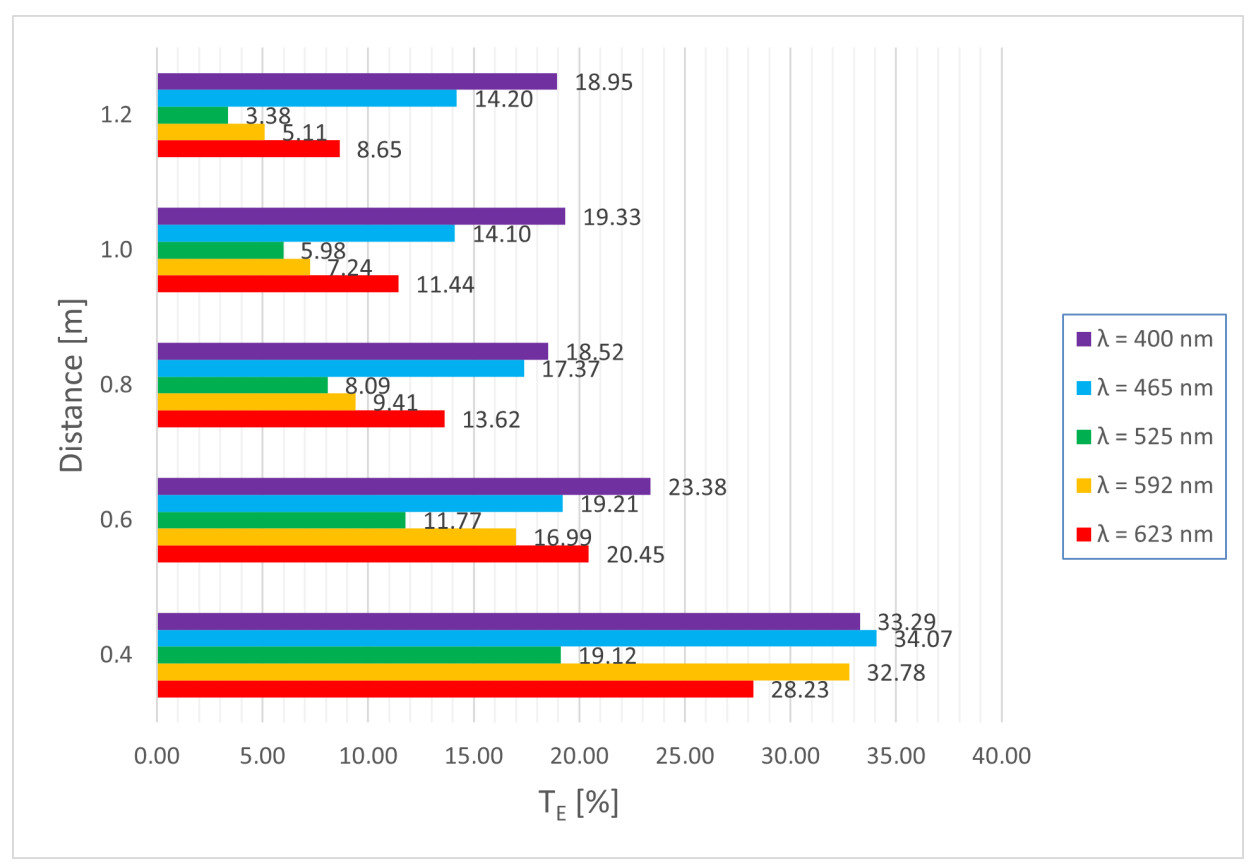

Figure 7. Average values of $\mathrm{T}_{E}$ transmittance at the study distances in the test smoke.

The analysis of the obtained results shows that the transmittance $\mathrm{T}_{E}$ value for the tested wavelengths decreases with increasing distance. The $\mathrm{T}_{E}$ values are below $35 \%$, and the differences in light transmission between the wavelength of light $\lambda=400 \mathrm{~nm}$ and the remaining wavelengths at the study distances are significant and amount to approximately $20 \%$. It should also be noted that, as the distance increases, the difference increases. There are also slight differences between the wavelengths $\lambda=400 \mathrm{~nm}$ and $\lambda=465 \mathrm{~nm}$ (ultraviolet and blue). In most cases, the wavelength of light $\lambda=400 \mathrm{~nm}$ has the highest penetration coefficient compared to other wavelengths, as confirmed by the ANOVA analysis of variance, Fisher NIR test and contrast analysis. The process of how transmittance changes for individual analyzed wavelengths is better illustrated in Figure 8. Considering the safety of people in the endangered zone, obtaining even a small improvement in visibility can be crucial; however, the upper ranges of the distances studied, 0.8 to $1.2 \mathrm{~m}$, are of the greatest importance. In a study [18], the author showed that, for visibility below that range, a significant decrease in the evacuation speed of people in the danger zone is noticeable. It applies in particular to irritant smoke. Hence, concerning the above, it should be pointed out that in the case of wavelengths $\lambda=525, \lambda=592$ and $\lambda=623$, the observed significant decrease in the obtained average values of the permeability coefficient in the given distance range indicates the potential of using shorter wavelengths (i.e., $\lambda=465$ and $\lambda=400$ ).

Additional information may be the distribution of results presented on a box plot (Figure 9). At the outset, it should be noted that there were no outliers in the set of obtained transmittances. An important observation is that, with the increase in distance, there was a smaller variability of the measured transmittances. This is particularly pronounced for longer light wavelengths $(\lambda=525, \lambda=592$ and $\lambda=623)$ at distances above $1 \mathrm{~m}$, which may be related to very low permeability at this range. 


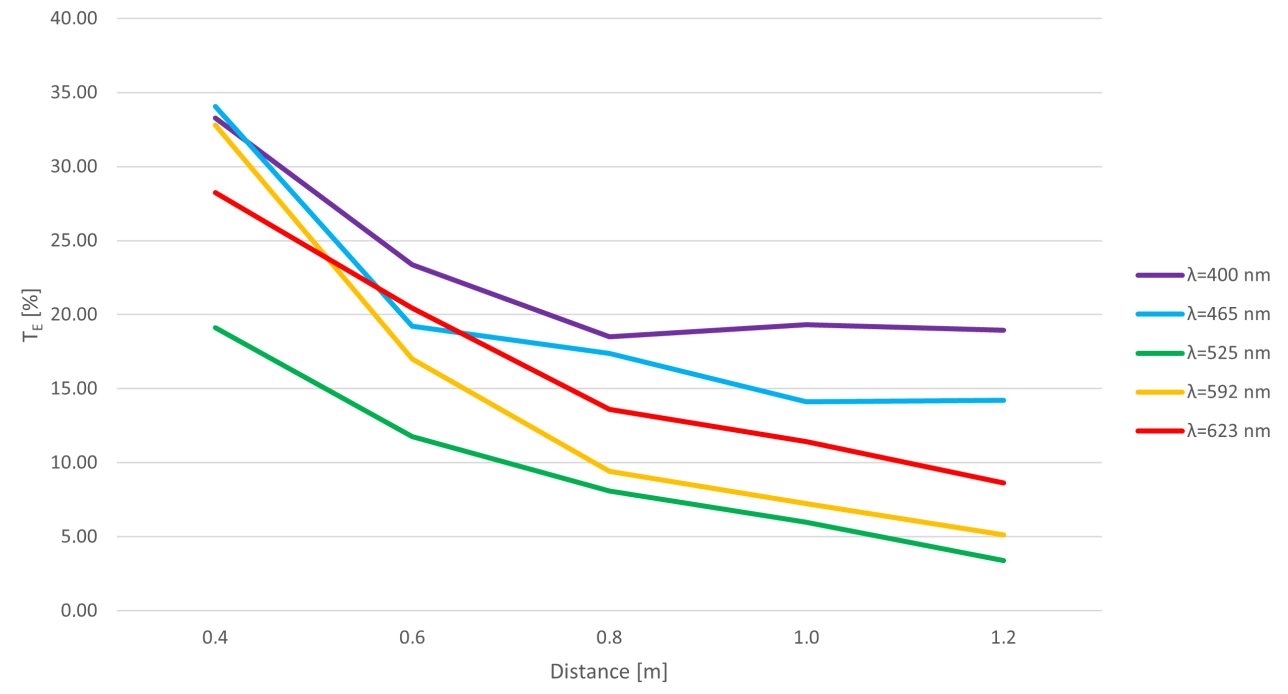

Figure 8. Average transmittance values $\mathrm{T}_{E}(\%)$ of wavelengths at specified distances in smoke.

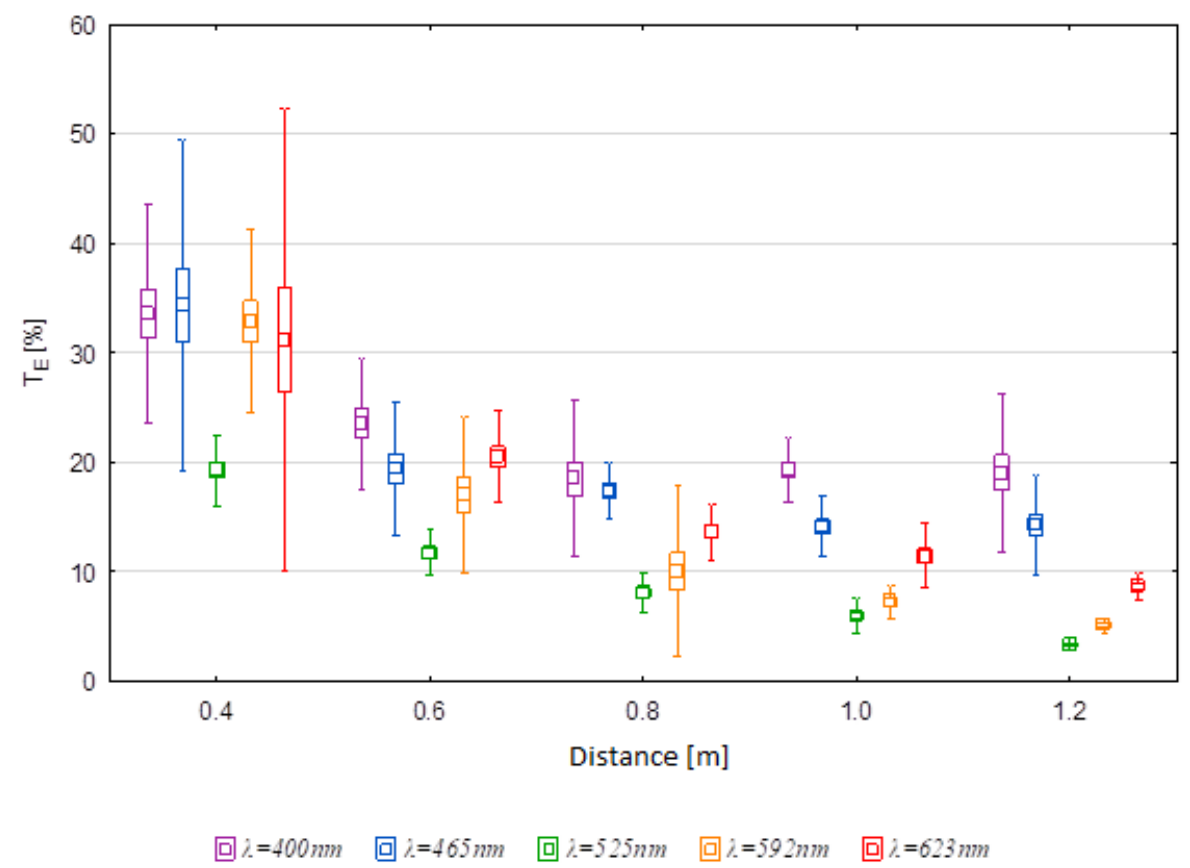

Figure 9. Box plot for the obtained values of transmittance $\mathrm{T}_{E}$ in smoke.

This research study also considered the subjective role of experts and their visual impressions as additional information. It should be noted here that the human eye adapts to night (scotopic) vision during which the human eye best perceives the wavelength of light $\lambda=507 \mathrm{~nm}$, corresponding to a blue-green colour. However, the used illuminance meter was calibrated according to the relative sensitivity curve of the human eye for photopic (daytime) vision, i.e., the wavelength $\lambda=555 \mathrm{~nm}$, corresponding to the yellow-green colour. However, this should not have a significant impact on the performed qualitative assessment. Employees of the State Fire Service, who take part in rescue and firefighting operations daily, were invited as experts. Surprisingly, the subjective indications of the experts participating in the experiment were entirely consistent. These opinions are summarized in Table 3. 
Table 3. Expert assessments of visibility in smoke depending on the light wavelength emitted ("+" visibility rated as the best by experts; "-" visibility rated as the worst by experts; " " the experts did not comment on the given light wavelength (it was not significantly important)).

\begin{tabular}{cccccc}
\hline Measurement Series Number & $\mathbf{1}$ & $\mathbf{2}$ & $\mathbf{3}$ & $\mathbf{4}$ & $\mathbf{5}$ \\
\hline wavelength $\lambda(\mathrm{nm})$ & - & & & & \\
400 & + & + & + & & + \\
465 & & & & + & \\
525 & - & & & \\
592 & & & & \\
623 & & & \\
\hline
\end{tabular}

Independent experts, in their opinions, indicated blue light $(\lambda=465 \mathrm{~nm})$ as the light at which the visibility range was the highest. Based on laboratory tests performed with a meter, this colour was also characterized by a high average transmittance value. It is also important to note that according to the experts' assessment, the visibility at ultraviolet light $(\lambda=400 \mathrm{~nm})$ was much lower than indicated by the transmittance measurements. It may be related to the low value of measured illuminance $E$ values for emitters of this wavelength and the fact that this value is close to the range of visibility of the human eye.

The results of the above analyses are reflected in the study of various light-length smoke permeability conducted as part of the project [27]. During the experiment, two different types of smoke were obtained by burning canola oil and juniper needles. A beam of white light was emitted by the smoke, and by using a spectrometer, the author measured how much of the light of different wavelengths passed through the medium. The performed experiments indicated, among other things, that at high smoke density the transmittance of light with wavelengths in the range corresponding to blue is the highest, those corresponding to red were significantly lower and yellow and green were extremely unfavourable. It should be mentioned that the preliminary research [28] also conducted by one of the authors of this publication in an artificial smoke chamber equipped with a stage smoke generator at the District Mine Rescue Station also showed similar regularities to those presented in this publication. In the context of the results obtained, the patented GLO-JO PAL ${ }^{\mathrm{TM}}$ product line [29] is also worth mentioning. This technology uses light in the blue/green light spectral range (blue light, aqua light and green Light) and is intended for firefighters working in conditions of reduced visibility (smoke or fog) or total darkness. However, published research on this solution is not available.

\section{Conclusions}

Based on the research results, their analysis and consulting experts opinions, it was stated that the wavelength of light (colour) has a significant impacts on visibility in smoke conditions.

In the dark smoke conditions resulting from the combustion of materials selected for the research study, it was found that at distances of $0.4 \mathrm{~m}$ and $0.6 \mathrm{~m}$, a high average value of $\mathrm{T}_{E}$ is obtained with a wavelength of $\lambda=623 \mathrm{~nm}$ (red). As the distance increased, a decrease in the tested transmittance was observed in favour of light with shorter wavelengths: $\lambda=400 \mathrm{~nm}$ (ultraviolet colour) and $\lambda=465 \mathrm{~nm}$ (blue colour). In the case of self-evacuation of people from the endangered area or conducting rescue operations in smoke conditions, the maximum visibility range is significant. In practical applications, the high transmittance values obtained for wavelengths (blue and ultraviolet) at a measuring distance exceeding $0.8-1.0 \mathrm{~m}$ are the most relevant.

Furthermore, it was necessary to compare the measurements obtained with sensors with the supportive opinions of experts participating in the experiment. These opinions indicated much better visibility when emitters with a wavelength of $\lambda=465 \mathrm{~nm}$ (blue colour) were in use than in the case of $\lambda=400 \mathrm{~nm}$ (ultraviolet colour). The indication of 
light with a length of $\lambda=400 \mathrm{~nm}$ as the worse case may be related to the fact that its value is close to the visible range of the human eye.

Based on the above information, the best usable visibility for people in an environment filled with dark smoke can be obtained by using blue light emitters with a wavelength of $\lambda=465 \mathrm{~nm}$.

The application of proper light to improve visibility in smoke-filled areas can improve safety during an evacuation or rescue operation.

Author Contributions: Methodology, N.K., A.P.N. and P.W.; formal analysis, N.K.; investigation, N.K. and A.P.N.; validation, N.K. and P.W.; data curation, N.K.; writing-original draft preparation, A.P.N.; writing-review and editing, N.K. and P.W.; visualization, N.K. and A.P.N. All authors have read and agreed to the published version of the manuscript.

Funding: This research received no external funding.

Institutional Review Board Statement: Not applicable.

Informed Consent Statement: Not applicable.

Data Availability Statement: The data presented in this study are available on request from the corresponding author. The data are not publicly available due to privacy restrictions.

Conflicts of Interest: The authors declare no conflict of interest.

\section{References}

1. Król, A.; Król, M. Numerical investigation on fire accident and evacuation in a urban tunnel for different traffic conditions. Tunn. Undergr. Space Technol. 2021, 109, 103751. [CrossRef]

2. Liu, B.; Mao, J.; Xi, Y.; Hu, J. Effects of altitude on smoke movement velocity and longitudinal temperature distribution in tunnel fires. Tunn. Undergr. Space Technol. 2021, 112, 103850. [CrossRef]

3. Tang, F.; Zhao, Z.; Zhao, K. Experimental investigation on carriage fires hazards in the longitudinal ventilated tunnels: Assessment of the smoke stratification features. Saf. Sci. 2020, 130, 104901. [CrossRef]

4. Tao, L.; Yan, X.; Zhang, Y.; Zeng, Y.; Fang, Y.; Bai, Y. Experimental and numerical study on the smoke and velocity distribution in an extra-long railway tunnel fire. Tunn. Undergr. Space Technol. 2021, 117, 104134. [CrossRef]

5. Aaralt, T.T.; Nilsen, A.R. Automatic fire detection in road traffic tunnels. Tunn. Undergr. Space Technol. 2009, 24, 75-83. [CrossRef]

6. Chen, H.; Chen, J.; Tan, J.; Zhang, J. Intelligent ventilation and emergency evacuation of underwater tunnel under fire conditions. Procedia Eng. 2016, 166, 379-388. [CrossRef]

7. Wang, M.; Guo, X.; Yu, L.; Zhang, Y.; Tian, Y. Experimental and numerical studies on the smoke extraction strategies by longitudinal ventilation with shafts during tunnel fire. Tunn. Undergr. Space Technol. 2021, 116, 104030. [CrossRef]

8. Tronstad, T.V.; Jenssen, G.D.; Moscoso, C.; Södersten, C.; Zaikonnikov, E. Sound signals to improve evacuation in road tunnels. Fire Saf. J. 2021, 125, 103431. [CrossRef]

9. Bjelland, H.; Nja, O.; Heskestad, A.W.; Braut, G.S. Emergency preparedness for tunnel fires-A systems-oriented approach. Saf. Sci. 2021, 143, 105408. [CrossRef]

10. Ronchi, E.; Fridolf, K.; Frantzich, H.; Nilsson, D.; Walter, A.L.; Modig, H. A tunnel evacuation experiment on movement speed and exit choice in smoke. Fire Saf. J. 2017, 97, 126-136. [CrossRef]

11. Xie, W.; Ming Lee, E.W.; Cheng, Y.; Shi, M.; Cao, R.; Zhang, Y. Evacuation performance of individuals and social groups under different visibility conditions: Experiments and surveys. Int. J. Disaster Risk Reduct. 2020, 47, 101527. [CrossRef]

12. Lambert, K.; Merci, B.; Gryspeert, C.; Jekovec, N. Search \& rescue operations during interior firefighting: A study into crawling speeds. Fire Saf. J. 2021, 121, 103269.

13. Schmidt-Polańczyk, N.; Burtan, Z.; Liszka, P. Simulation of the Evacuation of People in a Road Tunnel in the Event of Fire-Case Study. Arch. Min. Sci. 2021, 66, 13-28.

14. Wyższy Urząd Górniczy (State Mining Authority). Informacja Nr 16/2011 śm./EW. Available online: https://www.wug.gov.pl/ bhp/5_05_2011 (accessed on 13 September 2021).

15. Bai, J.; Liao, H.; Xia, Y. Study on Fire Accidents in Tunnels. IOP Conf. Ser. Mater. Sci. Eng. 2020, 741, 012095. [CrossRef]

16. Fraser-Mitchell, J.; Charters, D. Human Behaviour in Tunnel Fire Incidents. In Proceedings of the Eighth International Symposium 2005, Beijing, China, 18-23 September 2005; pp. 543-554.

17. Szewczyński, K.; Król, A.; Król, M. Should We Expect a Disastrous Fire Accident in an Urban Road Tunnel? Literature Data Review and a Case Study for Selected Tunnels in Poland. Sustainability 2021, 13, 6172. [CrossRef]

18. Jin, T. Studies on Human Behavior and Tenability in Fire Smoke. In Proceedings of the Fifth International Symposium 1997, Melbourne, Australia, 3-7 March 1997; pp. 3-21.

19. Jin, T.; Yamada, T. Irritating Effects of Fire Smoke on Visibility. Fire Sci. Technol. 1985, 5, 79-89. [CrossRef] 
20. Jin, T.; Yamada, T. Experimental Study of Human Behavior in Smoke filled Corridor. In Proceedings of the Second International Symposium 1988, Tokyo, Japan, 13-17 June 1988; pp. 511-519.

21. Zhang, Q. Image Based Analysis of Visibility in Smoke Laden Environments. Ph.D. Thesis, University of Hull, Hull, UK, 2010. Available online: https:// core.ac.uk/download/pdf/9841763.pdf (accessed on 13 October 2021).

22. Jin, T. Visibility and Human Behavior in Fire Smoke. In SFPE Handbook of Fire Protection Engineering; Springer: New York, NY, USA, 2008; pp. 2181-2206.

23. Rubini, P.A.; Zhang, Q.; Moss, J.B. Simulation of Visibility in Smoke Laden Enviornments. In Proceedings of the InterFlam 2007, 11th International Conference on Fire Science and Engineering, London, UK, 3-5 September 2007.

24. Przedsiębiorstwo Automatyzacji i Pomiarów INTROL S.C. Illuminance Meter User Manual TES-1335. Available online: http:/ / www.introl.pl/filedownload/ 608 (accessed on 20 September 2021).

25. Tissota, J.; Talbauta, M.; Yona, J.; Coppallea, A.; Besconda, A. Spectral study of the smoke optical density in non-flaming condition. In Proceedings of the 9th Asia-Oceania Symposium on Fire Science and Technology, Hefei, China, 17-20 October 2012; pp. 821-828.

26. Żak, I. Chemia Medyczna; Ślaska Akademia Medyczna: Katowice, Poland, 2001.

27. Appelmans, C.V. Seeing through the Haze: What Light Penetrates Wildfire Smoke? Project Number J1903; California State Science Fair, California Science Center: Los Angeles, CA, USA, 2009.

28. Drenda, J.; Koch, N. Badania wpływu długości fal światła na widoczność w sztucznym zadymieniu. Wiadomości Górnicze 2016, $12,683-686$.

29. GLO-JO ${ }^{\mathrm{TM}}$ Company. Available online: https://glo-jo.com/ (accessed on 15 September 2020). 